\title{
Students Studying Students: \\ An Assessment of using Undergraduate Student Researchers in an Ethnographic Study of Library Use
}

\author{
Allyson Washburn, Sheila C Bibb
}

\begin{abstract}
This paper reports on the use of undergraduate students enrolled in an Applied Anthropology course as researchers for a library use study at Brigham Young University's (BYU) Harold B. Lee Library (HBLL). This is a common practice at BYU, but has not been reported extensively in the literature. The study was carried out by the authors with the assistance of undergraduate students, the students being the researchers and was conducted in order that the HBLL could determine student ideas for reconfiguring some newly opened space in the Periodicals room. Using students assisted the library as well as met a curricular need in the Anthropology course. Ethnographic methods were the primary means used to gather the data. The paper asserts that the peer interaction during the data collection significantly enriched the quality of the data collected.
\end{abstract}

\section{Introduction: Using Student Researchers}

Brigham Young University is a private, coeducational, residential university with an annual enrollment of approximately 30,000 undergraduate students and 2,000 graduate students. The Library is classified as a research library and is a member of the Association of Research Libraries. With the exception of the library in the Law school, the HBLL is the sole university library. All library functions and resources, as well as subject disciplines areas, are spread throughout the six floors of the building. In addition to their teaching responsibilities, BYU professors, similar to faculty at other higher education institutions, engage in a rigorous program of research to stay abreast of developments in their respective fields. However, there is another research emphasis, not often seen at similar institutions.

An extremely important aspect of research at BYU is the institution-wide emphasis on mentoring undergraduates involved in research projects. Undergraduates assist faculty with research and creative work on campus, often working in labs and co-authoring papers with faculty members. The students' work, which often results in presentations, performances and publications in academic journals,

\footnotetext{
Allyson Washburn

Allyson Washburn received an MLIS from Brigham Young University and is Assessment Librarian in the Lee Library at Brigham Young University.

Email: allyson_washburn@byu.edu

\section{Sheila C Bibb}

Sheila C Bibb received an MPhil in Medical Anthropology from the University of Oxford and teaches Anthropology at Brigham Young University.

Email: sheila_bibb@byu.edu
} 
provides them with key credentials for graduate school admission or job placement. BYU undergraduates routinely win awards for their research while competing against graduate students.

(Undergraduate Research and Mentoring)

Consistent with this philosophy, "the university's Office of Research and Creative Actitivies awarded $\$ 588,600$ to 329 undergraduates whose research proposals merited grants. BYU also gave $\$ 1.5$ million to 80 faculty members specifically for projects involving undergraduates." (Ibid.)

This research practice is not a new phenomenon at BYU, in fact, the use of students to interact with other students is a long established tradition. As early as 1901, Karl G. Maeser, founding principal of Brigham Young Academy, the predecessor of Brigham Young University, established a system of students helping other students.

The system engaged the students in the Academy's daily operations, including maintaining department or classroom order, recording student performance, and mentoring younger students.

(Maeser (1901, p. 153) and Deseret News (1878, p. 829).

Maeser instructed faculty to identify students who needed help, so that competent tutors could be assigned to work with them (BYA Faculty Meeting Minutes 1878). Adopting a name widely employed by educational leaders elsewhere, Maeser called this the "monitorial system."

Over the years, the idea of monitoring has become mentoring with the development and implementation of the undergraduate mentoring program which BYU has sponsored since 2001. For this program faculty write Mentoring Environment Grants(MEGs) that include students as researchers on projects and students get the opportunity to work closely with a faculty member on his/her research. Student participants are often co-authors on faculty publications and present at national conferences. A few brief examples provided by the director of the Office of Research and Creative works at BYU will illustrate the types of projects in which undergraduate students have been involved.

Student involvement is one of the highlights of the Flourishing Families Project. More than 500 students have been involved throughout the whole process. Students help prepare questionnaires, perform interviews to collect data, enter data, analyze videos of the family and use the data to present professional papers and posters. Students also have a chance to work directly with the 7 principle investigators . . .

(BYU School of Family Life 2010)

Dr. Gregory Burton and his graduate student, Brandon Keele, have involved undergraduate students in a major research project, studying cells that harbor the Human Immunodeficiency Virus, or HIV. The students have trained on performing highly skilled functions, such as cloning and sequencing genetic data. Burton says, "Students participating in this mentored environment will learn skills 
that can benefit them as they pursue work in biotechnology, medicine and basic science.

(Reynolds, n.d.2)

\begin{abstract}
Dr. Laura Bridgewater's undergraduate students presented posters on osteoarthritis research at this year's Annual Meeting of the American Society for Biochemistry and Molecular Biology. Bridgewater says meeting officials were astounded that the posters were created by undergraduate students.
\end{abstract}

(Reynolds, n.d.12)

Author 2, one of the authors of this paper and a Principal Investigator in this study, together with another professor in the Anthropology Department, is currently mentoring students involved in a research project to determine the anthropological implications of the global flow of cocoa. For this project the students select a research question which particularly interests them regarding the production, processing, transportation, marketing and consumption of cocoa. They are then required to carry out individual research by conducting interviews, surveys, participant observation and applying other appropriate ethnographic methods in order to collect data. Once collected, they become responsible for the analysis and production of a professional report which can be presented at conferences and which will also become a chapter in a book devoted to the global flow of cocoa/chocolate.

Additionally, the authors have recently conducted another project for the HBLL using Applied Anthropology students. When students were asked in a course evaluation about this experience they made comments such as:

I have always been a little nervous about doing real things. Reading about projects made it seem like something beyond what normal people did. I feel like I am so much more prepared [after this project] to enter some sort of professional world and actually do something at least semi-independently. DR.

I think it was a great experience and a valuable job skill. I listed it as an accomplishment on my resume and people were impressed by it. LP.

From these, and other similar comments, it is easy to see that the students being asked to carry out the research not only enjoyed what they did, but are grateful to have had the practical experience it afforded them. Students as researchers working closely with faculty mentors would seem to have much to commend it. However, we have taken this a stage further on the premise that most people respond more positively and naturally to their peers than to a random mix of age, social, and educational background. Because we wanted to know what undergraduate students think about the services offered by the University library, how they utilized them and why, it seemed obvious that we would get much more accurate information if we used a group of BYU undergraduate students to actually ask the questions. It was also obvious that the researching students needed to be trained to carry out the exercise effectively, hence the decision to use Anthropology students trained in ethnographic methods. It was on this premise that we carried out the study and the remainder of this paper looks in more detail at what was done, how it was done and why, and then examines the results 
obtained in order to not only assess how valuable it was to the HBLL, but also to determine whether our hypothesis about peer groups was correct.

\section{Context}

During a library renovation completed in 1999, a new Periodicals room was added to accommodate both current and historical print copies in a single location. In the ensuing years, as is true of many research libraries, the majority of periodical subscriptions are now delivered electronically. Recently the library began building an in-house auxiliary storage area (AuxStor) to house groups of older, less used periodicals. The Periodicals department had already begun moving the aforementioned periodicals to this area and using students to page requests. Subsequent to his visit to a BYU Student Advisory Council (SAC) meeting, the university librarian reported that the Periodicals room was a preferred quiet study space, and directed that more periodicals be moved into AuxStor. The assessment librarian proposed that a study be undertaken to validate the SAC's views and to ascertain a wider range of student views on preferred uses of the space.

\section{Methodology}

The study was carried out collaboratively by the authors, an anthropology professor and a librarian, with the assistance of undergraduate students in an Applied Anthropology class. This particular class was chosen because the curriculum of the course included a project in which the students would conduct a study using some of the methodologies they had been learning in their program. Other studies of the type reported here have been undertaken by other anthropologists in recent years ( Asher, Duke \& Green 2010; Hobbs \& Klare 2010; Smale \& Regalado 2010; Gabridge, Gaskell \& Stout 2008; Webb, Schaller, \& Hunley 2008; Foster \& Gibbons 2007) with the major differences being that most of them used an anthropologist and/or library employees to gather the data and the time frame for the data collection varied between one and two years. Using undergraduate students is an unusual methodology, especially since the principal investigators in the study collected none of the study data. However, two examples of the use of student researchers, one using undergraduate students and one done by a graduate student, has been documented in the literature. Delacore, Mullooly \& Scroggins' study of the Fresno State library used undergraduate students enrolled in an ethnographic methods course to assist with the research.

Under the supervision of Delacore, Mullooly and Scroggins [Field Project Director], the student researchers worked on every stage of the project, including participant recruitment, observations, interviews and data analysis.

(Delacore 2009)

A second example was reported by Bryant, a student in Loughborough University's Information and Library Management program, when she undertook her study of Loughborough University's flexible learning space for her Master's dissertation (Bryant, 2009, 4). In this case, Bryant was not an undergraduate and was the sole researcher. Beyond indicating that students acted as researchers, 
neither of these studies commented extensively on the use of student researchers that is the focus of this article.

The main objective of this study was to determine student ideas for reconfiguring some newly opened space in the Periodicals room at the Harold B. Lee Library (HBLL) at BYU, with the data gathering expanded to include student use of the entire library. The study was conducted during fall semester, 2009, when the Applied Anthropology class was taught. Students in the course were oriented to the objectives of the study early in the semester. Class lectures and group work included information and training on conducting focus groups, interviewing participants and the ethics and confidentiality required in this type of study.

Four teams of student researchers were created, Design Charette, Interviews, Time-Use Diaries, and Surveys. The Design Charette team observed students in the Periodicals room to determine how they currently use it. They then conducted semi-structured interviews with students in the room, and had a separate group of students redesign the room and discuss their recommendations during a focus group. The Interview team divided the campus into zones and conducted semistructured interviews with students in each zone about their current use of the library, the areas in the library they liked/used most and what they wished the library provided, facilitated, or allowed. Additionally, they interviewed library and university student support staff about their perceptions of student library use. The Diaries team asked participants to keep a time-use diary, recording their daily activities for a three week period, a photographic diary of activities, places and objects that were part of their daily life, and a mapping diary of everywhere they went for one day on campus. The Survey team conducted a face-to-face Undergraduate Experience survey and an email library-use survey. The authors acted as principal investigators and each mentored two teams, but as mentioned earlier, did not participate in any data collection for the study.

At the end of the data gathering period, each group analyzed their data and each member of the group wrote an individual report of their findings along with recommendations for the library. The authors also analyzed all the data to determine if the students' analysis supported the data they had collected. A formal report was written and delivered to the library's Administrative Council and the authors were invited to present the findings and recommendations to that body.

\section{Findings}

In order to illustrate the importance of using students the authors will briefly review the major findings of the study. From the many results thus gathered we found that in fact the same issues are a major concern for all students, irrespective of gender, class, or research method employed. Basically these can be summarized as follows:

- The Library is a place to study/do homework.

- It needs to be quiet, with a comfortable (homey) ambience and also be aesthetically pleasing.

- It needs to have plenty of computers, more working outlets, and more Mac computers available. 
- Students also seem to require space in which to spread themselves and their belongings out, so are rarely willing to sit more than two to a table.

- Another prime feature is that of easy access and as such a south entrance is requested since most students, once on campus, are actually situated in areas to the south of the Library.

- There was also a concern that food should be allowed in at least one or two restricted areas.

- Additional needs included a perceived need for better, preferably natural, lighting; more group study areas, and features which would help to reduce stress - for example plants, water features, art works.

Of particular interest was the fact that none of the suggested redesigns of the Periodicals room, nor any of the focus group comments, mentioned existing services in the room or requested additional services in the room.

Recommendations made to the library's Administrative Council incorporated these findings and ranged from the aesthetic to the technical. Aesthetic improvements included softer, more natural lighting, artwork and plants, more comfortable seating and a set apart reading lounge. Providing more computers, especially Macs, additional outlets, ensuring that existing outlets are activated and working, and creating more group study areas rounded out the technical recommendations. While these findings are not of themselves of importance for this paper, it is the reasoning behind them which validates the use of student researchers.

\section{Benefits of using student researchers}

The decision to use students to study students was adopted for three basic reasons.

- The first was that students provided a larger pool of available researchers ( 25 in all) who were able to carry out the research requirements, including the approach to students, not just within the library but elsewhere on campus, and to do so within a minimal time frame. Similar studies have been conducted principally by one or two principal investigators with the help of some librarians or a few student research assistants.

- Second, multiple methods of data collection were employed, and subsequently, enabled a larger amount of data to be collected in a shorter period of time than the authors working together could have done, given their daily teaching and librarianship commitments.

- Third, carrying out an actual study was a bonus for the students and gave them valuable experience they would otherwise not have gained. As the course evaluation showed, those participating were very enthusiastic as evidenced by these comments:

"I love how we don't just learn how we can apply Anthropology but that we actually get to do it." $A H$

"It gave us a chance as students to really play the part of researcher and perform actual research and analyze actual data ... it was extremely helpful to take what we learned in class and put it for a test run." JG. 
Finally, but in many ways the most important aspect, was the hope previously mentioned, that those interviewed would speak more freely and accurately if interviewed by their peers rather than someone who is obviously faculty. Using this same reasoning, the student assigned to carry out faculty/staff interviews outside the library was a mature student who is employed part-time by the university in an administrative capacity and who was therefore better able to relate to those she was interviewing.

The collected data reflected what informants actually did, most times with a detailed explanation of why, rather than what they thought they should say to an adult, especially a librarian, asking them for the same information. For example, many students commented that if they could find a quiet place, with access to food and a computer in another building, especially one where they had classes, they stayed there rather than coming to the library. When asked why they chose particular areas in the library for studying, one student reported that a relationship had just ended and she wanted to be somewhere where no one would see her if she began to cry. Students interviewed in the Periodicals room admitted to never or very seldom using the print periodicals and some even admitted they didn't know what a periodical was or what it was for. Several students in a focus group admitted ignorance of basic services routinely provided by the library. We also found that the Library Administrators' efforts to make the library seem 'homey,' by displaying works of art, was not the success they had hoped it would be. Simply, the works displayed were of a modern genre calculated to appeal to the students, whereas the students themselves said they found these pieces to be distracting, loud, jarring and requested they be replaced with traditional works which would be pleasant to look at and not stress-inducing.

Perhaps the greatest, and most valuable, impact of the team findings was the triangulation effect, or the extent to which each groups' findings reflected the findings of the other groups, thereby giving them a degree of validity which might not otherwise have been possible. For instance, no matter which data collection method was used, students reported that the number one reason they came to the library was to study and furthermore, again reported from all groups, that they came to study in the library because it was quiet. Moreover, the qualitative data collected corroborated the quantitative data collected. Students who responded to the survey reported that more outlets were needed all over the library. However, it wasn't until a reading of the interview transcripts that the reason for this emerged. Much group work was going on in open group study areas with students using their laptops. Because of the short battery life of laptops, they had to take turns plugging their laptop into a power source, thus greatly reducing their efficiency in getting their work done. Another item on the survey revealed that students overwhelmingly would like a south entrance to the library, the current library only having one entrance on the north. The library has heard this before, but when the campus maps from the mapping exercise were examined, it became apparent that most of the places, including classroom buildings, students were going to are south of the library.

Another example of the qualitative confirming the quantitative was discovered when analyzing the interview and survey data. In response to the changing nature of student research practices and service expectations of the library, the General 
Reference area on the main floor of the library was reconfigured as an Information Commons. The commons includes collaborative and individual computer stations and a multimedia lab where students can check out equipment for use in projects and then use the computers in the lab to create, edit, and produce audio and video materials.

The quantitative results indicated that one of the most popular/used areas is the library's Learning Commons - the 'No Shhh' zone. Interviewees were asked which areas of the library they 'liked best' and 'used most.' Looking at the results for the interview question "which part of the library do you dislike?" among all groups of students the number one answer was the 'No Shh' zone. This contradiction was resolved when the authors looked more closely at why the students responded as they did. Further elucidation revealed that when required to work as a group, students find the 'No Shh' zone to be a good area but in all other instances most prefer the quiet atmospheres found elsewhere in the library. This 'triangulation' effect is most important in any study which has a large qualitative component, as this one certainly has, because the various factors not only corroborate each other but also set the limits within which an agreed finding will be determined.

\section{Limitations of using student researchers}

It may also be appropriate at this time to make some comments on the limitations associated with using students to do this study. The most significant one was that some groups decided to form sub-teams to accomplish the various tasks for their group. This resulted in some group members commenting that often they did not know what the other teams in their group were doing or, alternatively, that they lacked an overall understanding of the purpose of how their particular activities related to what the rest of the sub-groups were doing. It is debatable as to what extent this failure to comprehend the bigger picture actually impacted on the work they carried out. Another challenge was the use of multiple interviewers which on occasion resulted in varied wording of the questions asked and some dividing or combining of questions. Also, some groups had difficulty finding willing participants for the interviews, surveys and for the design exercise. It is difficult to tell whether this was a limitation directly associated with using students as researchers, or whether this problem would have arisen anyway.

Limitations also surfaced in using students to do the surveys. Perhaps the factor which had the biggest impact here was that the surveys had already been written by a faculty member and the students therefore felt that their role in the study wasn't that important, even though they did make some amendments. They did not seem to understand the purpose of the Undergraduate Experience survey nor how the findings would inform this study. Because statistical correlations were not possible for either survey, they felt that their time was wasted and that the surveys had little or no value. Consequently, their analysis of the information in the surveys was extremely limited .In reality, despite the apparent lack of statistical correlations, the surveys yielded much significant contextual information which helped build up a much fuller picture of student life and library usage and facilitated a greater understanding of the results produced by the other groups. 
Finally, it should be noted that with each group of researchers, there were strengths as well as limitations and some groups were meticulous in their approach, organizing themselves in a professional manner and being critically aware in their resulting write-up. These groups not only accomplished their goals but produced good group analyses and were able to both recognize and comment upon areas of doubt, as well as the positive factors which emerged.

It is also a fact that many libraries do not have the funds to retain an anthropologist to assist with studies such as this one. However, if they have connections with an active anthropology department on campus, using students as researchers could provide a valuable pool of peer investigators for the library as well as providing the students with a real world experience. In the authors' current set-up, Applied Anthropology is a 200 level course and includes students from freshmen to seniors. Subsequent research could be done to determine if seniors have more experience, have a better knowledge of methods, and consequently do a better job.

\section{Summary}

The study reported here has thus far resulted in action being taken on three of the major recommendations provided in the report prepared for the library administration. This has helped the student researchers to see that their work, i.e., the activities they carried out and the data they collected, was actually used to make changes in the library. In the past students had to design a project and plan what they would do if they actually carried it out. Other times students did internships or service projects and commented on them, but they did not carry out the actual study. This resulted in a theoretical understanding of what Applied Anthropology was but did not provide them with an actual experience. In contrast, the research questions were provided by the authors, but the students planned the methodology and actually carried out the data collection and the initial analysis. Consequently, they felt ownership for the project and felt that they had left a permanent contribution for their peers. Additionally it improved the subsequent study in which the authors and students are presently engaged. Could we have done this without the use of students? Probably, but it would have taken much longer and would have limited the variety of methods utilized.

Furthermore, students would not have responded to us as well as they did their peers, thus making the data less authentic. It is felt however, that further research is needed to establish a set of best practices for using student researchers.

Currently, the authors and the Fall 2010 Applied Anthropology class are engaged in a second study to understand how students approach and carry out their work to complete papers or assignments requiring library research, what the faculty expectations for such assignments are and how the final product the student produces matches those expectations. Information about the use of the library, its services and resources will enable the library to evaluate current practices to determine if changes need to be enacted to better support and assist students completing such assignments. 


\section{Conclusion}

In this paper we have outlined our approach to a library assessment problem where we decided to carry out a short-term, or rapid assessment, study using undergraduate students as the researchers. We have explained our reasoning for this move and reported the outcomes. This leads us to reconsider the basic premise on which we built our study - the notion that using a peer group, i.e. , undergraduate students, to actually study the library use habits of other undergraduate students, would furnish a more complete and reliable picture and produce data that the HBLL could confidently act upon. We have shown that not only were we able to triangulate our findings and thus validate them, but we were also able to explain why students felt as they did. The many 'informal' comments and stories which the researchers reported not only gave much valuable information but also confirmed our belief that those being studied did in fact respond more fully and accurately when speaking to a peer. We therefore conclude that our hypothesis regarding the use of students to study students was correct. This being so we are not only using this same method to engage in our current study, but advocate it as a worthy tool for other libraries and similar institutions to use when carrying out an assessment. 


\section{References}

Asher, A. , Duke, L. \& Green, D. (2010), 'The ERIAL project: Ethnographic research in Illinois academic libraries', Academic Commons, May 2010,

"Advancing Towards Liberal Arts 3.0", viewed 7 September 2010 <http://www.academiccommons.org/commons/essay/erial-project>.

‘Brigham Young Academy of Provo' 1878, Deseret News, 30 January, p. 829.

Brigham Young University School of Family Life, (2010) Flourishing Families Project, viewed 5 November 2010, <http://familylife.byu.edu/>

Bryant, J (2007), 'An ethnographic study of user behaviour in Open3 at the Pilkington Library', Master's Dissertation, Loughborough University, Leicestershire, UK, viewed 10 October 2010, < https://dspace.lboro.ac.uk/dspace-jspui/handle/2134/3136>.

Bryant, J. (2009), 'What are students doing in our library? Ethnography as a method of exploring library user behavior', Library and Information Research, vol. 33. no.103, pp.3-9.

BYA Faculty Meeting Minutes, holographic reprint, February 22, 1878, 46, in Meeting Minutes, 1876-1951, UA5, L. Tom Perry Special Collections, Harold B. Lee Library, Brigham Young University, Provo, Utah.

Delacore, HD, Mullooy, J \& Scroggins, M. with Arnold, K, Franco, E. and Gaspar, J. (2009), The library study at Fresno State, The Institute of Public Anthropology, California State University Fresno, viewed 23 November 2009, $<$ http://www.csufresno.edu/anthroplology/ipa>.

Foster, NF \& Gibbons, S (eds.) (2007), Studying students: The undergraduate research project at the University of Rochester. Association of College and Research Libraries, a division of the American Library Association, Chicago, IL.

Gabridge, T, askell, M \& Stout, A (2008), 'Information seeking through student's eyes: The MIT photo diary study', College \& Research Libraries, vol.69, no. 6, pp. 510-522.

Hobbs, K \& Klare, D (2010), 'User driven design: Using ethnographic techniques to plan student study space', Technical Services Quarterly, vol. 27, no. 4, pp. 347-363.

Maeser, K. G. (1898), School and fireside, Skelton and Co., Salt Lake City, UT.

Maeser, K. G. 1901, 'The monitorial system', Juvenile Instructor, pp. 153. see also Maeser, School and Fireside (Salt Lake City: Skelton and Co., 1898), 272.

Reynolds, G. (no date) Examples of principles of mentored learning at Brigham Young University, Office of Research and Creative Activities, Brigham Young University, Provo, UT.

Smale, M. A. \& Regalado, M. ( 2010), Undergraduate Scholarly Habits Ethnography Project, viewed 10 June $2010<$ http://ushep.commons.gc.cuny.edu/preliminary-results >. 
Brigham Young University (2010), Undergraduate research and mentoring, Brigham Young University, viewed 11 November 2010,< http://yfacts.byu.edu/viewarticle.aspx?id=140>.

Webb, KM, Schaller, M \& Hunley, S. A. (2008), 'Measuring library space use and preferences: Charting a path toward increased engagement', portal: Libraries and the Academy, vol. 8, no. 4, pp. 407-422.

\section{Acknowledgement}

The authors wish to acknowledge the support given them by Brigham Young University, the Harold B. Lee Library, and the Anthropology Department in allowing this study to take place and for their encouragement to pursue and develop alternative methods of research. They also thank the various Anthropology students involved for their hard work in carrying out their assigned tasks and making this study the success it has proven to be. 